\title{
DESAIN DATA WAREHOUSE PADA SISTEM INFORMASI SUMBER DAYA MANUSIA SUB-SISTEM REKRUTMEN
}

\author{
Eka Miranda \\ Information Systems Department, School of Information Systems, Binus University \\ Jln. K.H. Syahdan No. 9, Palmerah, Jakarta Barat 11480 \\ ekamiranda@yahoo.com
}

\begin{abstract}
Employees as a resource management are essential to improve the effectiveness of company's performance and process efficiency. This paper discusses the implementation of data warehouse and its role in assisting the decision making related to recruitment activities undertaken by Human Resources Department. In this research built a data warehouse design to store large amounts of data and to gain potentially a new perspective of data distribution as well as to provide reports and solutions for users the ad hoc question and to analyze the transactional data. This study aims to design a data warehouse to support accurate decision making related to human resource management in order to create high performance productivity. The method used in this paper consists of: (1) data collection using interview and literature study related to employee recruitment and (2) data warehouse design derived from Teh Ying Wah et al. This research results in a data warehouse design and its implementation to analyze transactional data from the related activities of recruitment and employee management to support decision making.
\end{abstract}

Keywords: HR, recruitment, Data Warehous

\begin{abstract}
ABSTRAK
Pengelolaan karyawan sebagai sumber daya sangat penting untuk meningkatkan efektivitas kinerja serta efisiensi proses bagi perusahaan. Tulisan ini membahas implementasi data warehouse dan peranannya dalam membantu pengambilan keputusan yang terkait dengan kegiatan rekrutmen yang dilakukan departemen Sumber Daya Manusia. Pada penelitian ini dibuat desain data warehouse untuk menyimpan data dalam jumlah besar dan juga berpotensi untuk mendapatkan sudut pandang baru dari sebaran data dan memungkinkan untuk memberikan pelaporan dan jawaban dari pertanyaan pengguna yang bersifat ad hoc termasuk juga untuk melakukan analisis data transaksional. Penelitian ini bertujuan merancang data warehouse untuk mendukung pengambilan keputusan yang akurat terkait pengelolaan sumber daya manusia untuk menciptakan produktivitas kerja yang tinggi. Metode penelitian yang digunakan adalah pengumpulan data melalui wawancara dan studi pustaka terkait dengan perekrutan karyawan, yang dilanjutkan dnegan perancangan data warehouse yang bersumber dari Teh Ying Wah et al. Hasil dari tulisan ini berupa desain data warehouse serta implementasinya untuk menganalisis data transaksional dari kegiatan yang terkait perekrutan dan pengelolaan karyawan untuk mendukung pengambilan keputusan.
\end{abstract}

Kata kunci: sumber daya manusia, rekrutmen, data warehouse 


\section{PENDAHULUAN}

Sumber Daya Manusia (SDM) merupakan salah satu sumber daya yang sangat penting bagi suatu organisasi. Pengelolaan SDM yang tepat selalu menjadi perhatian penting dari setiap manajemen organisasi untuk mencapai efektifitas dan efisiensi proses-proses yang berlangsung dalam organisasi dan untuk itu memerlukan pengelolaan informasi yang terpadu. Salah satu upaya untuk meningkatkan efektifitas pengelolaan informasi SDM adalah dengan menggunakan data warehouse yang diharapkan dapat menyajikan informasi strategis (Riyanto \& Sucahyo, 2006). Dengan adanya penerapan sistem yang baik dan tepat di departemen SDM, diharapkan organisasi atau perusahaan memiliki kemampuan bersaing, tampil lebih profesional dan meningkatkan kinerjanya.

Saat ini perusahaan menggunakan database untuk meyimpan record transaksi yang dimiliki mereka. Database tidak dapat secara langsung digunakan untuk membantu analisis dan pengambilan keputusan. Untuk membangun sistem pengelolaan data yang baik dibutuhkan kemampuan analisis data transaksional yang digunakan dengan optimal. Analisis yang tidak optimal biasanya disebabkan oleh tidak semua data dioptimalkan penggunaannya dengan baik untuk menghasilkan pengetahuan yang bermanfaat bagi manajeman perusahaan untuk membantu dalam pengambilan keputusan. Pengembangan data warehouse ditujukan untuk mengintegrasikan, menggali dan membuat intisari informasi yang penting dari data yang tersebar.

Data warehouse tidak hanya digunakan untuk menyimpan data dalam jumlah besar dan juga berpotensi untuk mendapatkan sudut pandang baru dari sebaran data dan memungkinkan untuk memberikan pelaporan dan jawaban dari pertanyaan pengguna yang bersifat ad hoc termasuk juga untuk melakukan analisis data transaksional dari kegiatan yang terkait dengan perekrutan dan pengelolaan karyawan. Perancangan data warehouse pada Sistem Informasi Sumber Daya Manusia (SDM) sub-sistem rekrutmen ini diharapkan dapat membantu departemen SDM dalam menggali dan mendapatkan intisari informasi yang diperlukan untk melakukan analisis data dan mendukung pengambilan keputusan yang berkaitan dengan kegiatan perekrutan dan pengelolaan karyawan.

Masalah yang diformulasikan dari kasus desain data warehouse pada sistem informasi sumber daya manusia sub-sistem rekrutmen terdisi atas: kenyataan bahwa perusahaan memiliki banyak data tetapi kurang akan informasi yang berkualitas, diperlukannya efisiensi waktu dan proses untuk menghasilkan informasi yang terintegrasi yang dibutuhkan dalam menganalisis dan mengambil keputusan, dan diperlukan perangkat analitik yang kemudian digunakan secara optimal untuk mendukung pengambilan keputusan.

Tujuan dari penulisan ini adalah untuk menjelaskan bagaimana merancang data warehouse untuk mendukung pengambilan keputusan yang akurat terkait pengelolaan sumber daya manusia untuk menciptakan produktivitas kerja dan loyalitas yang tinggi sehingga produktivitas perusahaan dapat lebih ditingkatkan.

\section{METODE}

Metode yang digunakan pada tulisan ini terdiri atas: Teknik pengumpulan data menggunakan teknik wawancara dan studi pustka terkait dengan perekrutan karyawan dan Teknik perancangan data warehouse menggunakan tahapan perancangan data warehouse yang bersumber dari Wah, Teh Ying, Peng, Building Data Warehouse (2007). 
Membuat data warehouse tidak sekedar memindahkan data opersional ke dalam data warehouse. Memindahkan data dari beberapa sumber berpotensi menimbulkan masalah besar terutama terkait dengan isu tidak konsistennya data. Data warehouse tidak hanya digunakan dalam melakukan loading, integrasi, dan menyimpan data dalam jumlah besar, tapi juga berpotensi untuk mendapatkan sudut pandang baru dari sebaran data, dan memungkinkan untuk memberikan pelaporan dan jawaban dari pertanyaan pengguna yang bersifat ad hoc secara cepat dan lebih baik. Tahapan untuk membangun data warehouse terdiri atas: identifikasi sumber data, membangun ETL (extraction, transformation, loading) tool, ekstraksi, transformasi, dan loading.

\section{Identifikasi sumber data}

Langkah pertama sebelum mulai mengembangkan data warehouse yaitu identifikasi sumber data. Perlu mencari tahu apa data yang dibutuhkan untuk diletakkan ke dalam data warehouse.

\section{Membangun ETL (Extraction, Transformation, Loading) tool}

Setiap data warehouse memiliki data yang berbeda persyaratan, oleh karena itu, ETL tool yang sesuai adalah solusi yang lebih baik untuk memenuhi persyaratan.

\section{Ekstraksi}

Perlu menentukan sistem database yang akan digunakan dan juga mencari tahu data apa yang diperlukan sebelum mendapatkannya. Penurunan biaya perangkat keras dan penyimpanan telah mengatasi masalah pada menghindari duplikasi data dan juga kekhawatiran pada kurangnya ruang penyimpanan sebagai tempat penyimpanan data yang berlebihan atau yang tidak diperlukan. Namun, mungkin tidak ada alasan untuk menyimpan data yang tidak diperlukan dan telah diidentifikasi tidak berguna dalam proses pengambilan keputusan. Oleh karena itu, diperlukan untuk mendapatkan hanya ekstrak data yang relevan sebelum membawa ke data warehouse (Mallach, 2000).

\section{Transformasi}

Setelah penggalian data dari berbagai sumber, transformasi dibutuhkan untuk menjamin konsistensi data. Agar mengubah data ke dalam data warehouse dengan benar, perlu mengetahui cara pemetaan bidang sumber data eksternal ke data warehouse. Transformasi dapat dilakukan selama ekstraksi data atau saat memuat data ke dalam data warehouse. Integrasi ini bisa menjadi masalah yang kompleks ketika jumlah sumber data menjadi lebih besar.

\section{Loading}

Setelah proses penggalian, mengubah dan pembersihan telah dilakukan, data diambil ke dalam data warehouse. Pemuatan data dapat dikategorikan ke dalam dua jenis; pemuatan data yang saat ini ada dalam database operasional dan pemuatan pembaruan data warehouse dari perubahan yang telah terjadi dalam database operasional. Untuk menjamin kesegaran data, data warehouse perlu untuk terus memperbaharui datanya. Banyak persoalan yang perlu untuk dipertimbangkan terutama saat memuat data yang sudah diperbaharui ke data warehouse. Sementara melakukan pemutakhiran data warehouse, perlu memastikan bahwa tidak ada data yang dilepaskan dan juga untuk memastikan overhead minimum selama proses scanning file yang ada (Teh Ying Wah et al., 2007).

Berikut adalah gambar arsitektur data warehouse (Vercellis, 2009, pp.51-52) (Gambar 1): 


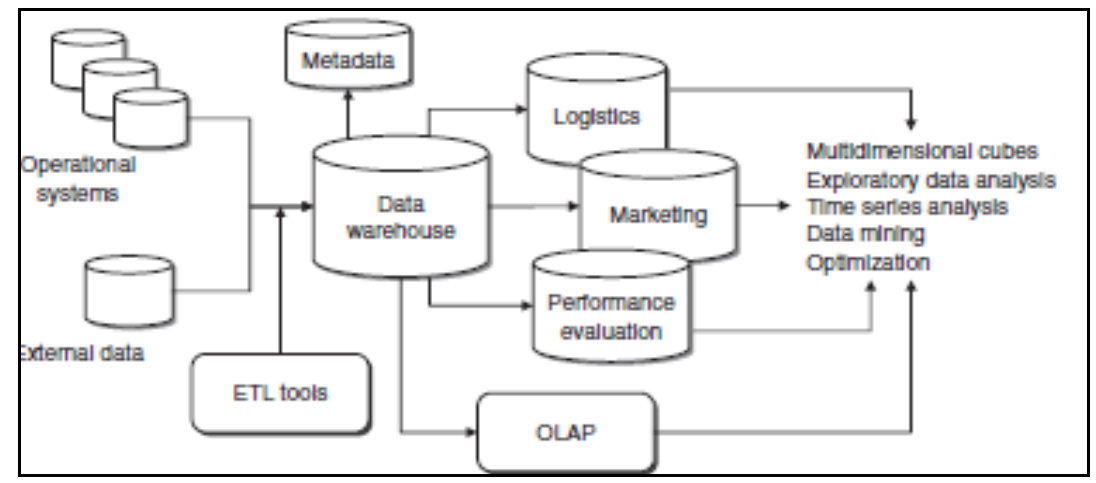

Gambar 1. Arsitektur dan fungsi data warehouse.

Data warehouse bersama dengan data mart tambahan yang berisikan data dan fungsi yang dapat diakses, ditampilkan dan diubah. Pengakuisisian data disebut sebagai proses Extract transform Load (ETL), yang memungkinkan data diseleksi, ditransformasi dan disimpan ke dalam data warehouse.

\section{HASIL DAN PEMBAHASAN}

\section{Rancangan Basis Data Sistem Informasi SDM Sub-Sistem Rekrutmen}

Basis data Sistem Informasi Sumber Daya Manusia Sub-Sistem Rekrutmen terdiri atas Tabel Pegawai, Tabel Jabatan, Tabel Departemen, Tabel Pelamar, Tabel Penilaian (Gambar 2).

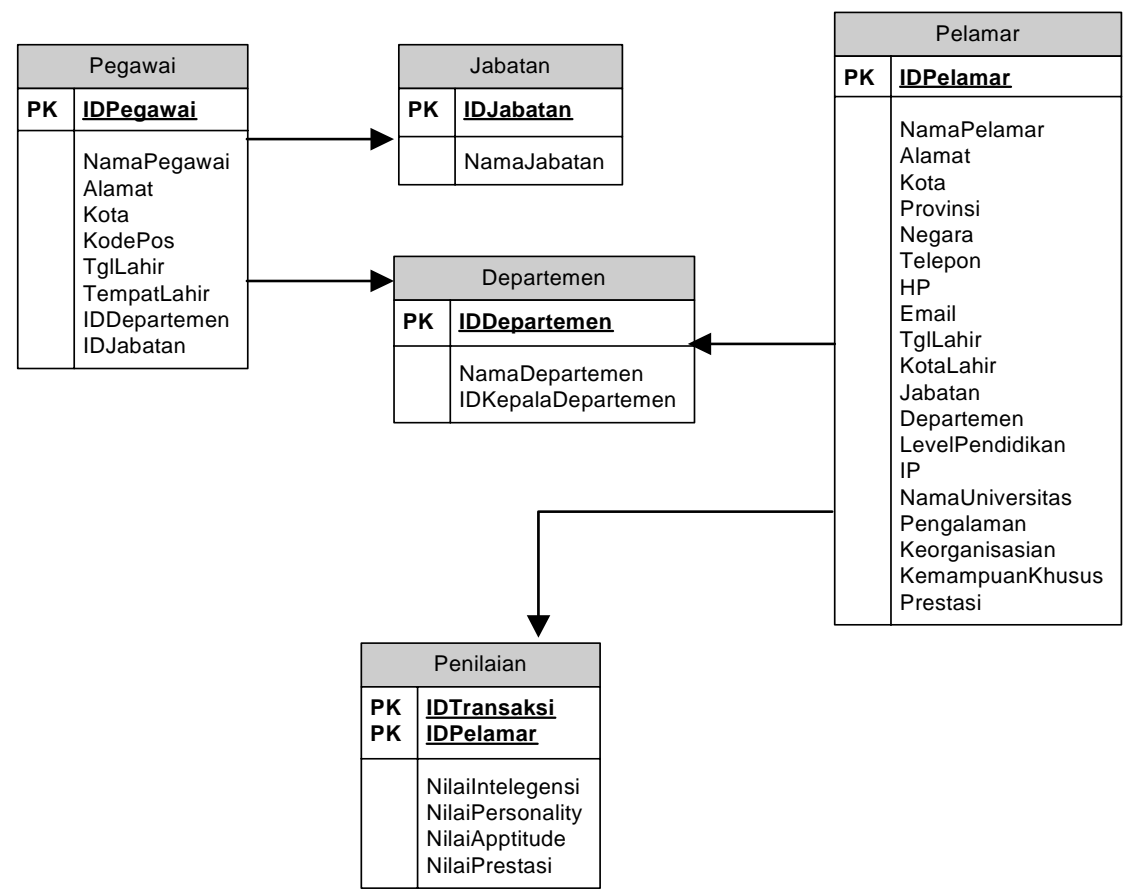

Gambar 2. Rancangan basis data model pengambilan keputusan. 


\section{Pengumpulan dan Analisis Data}

Kegiatan rekrutmen yang dilakukan oleh departemen SDM beserta atributnya adalah sebagai berikut (Gambar 3).

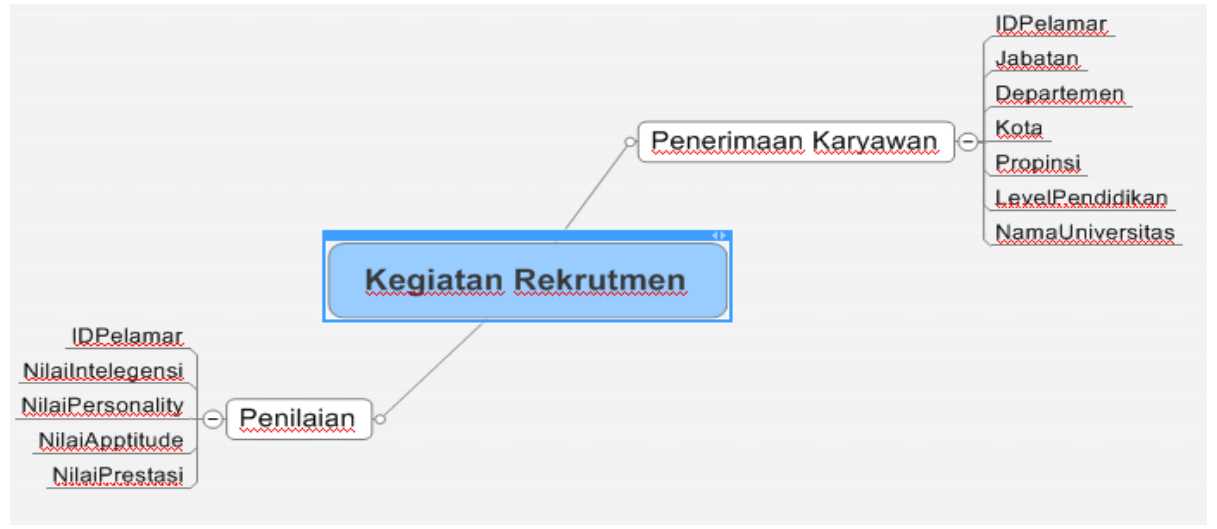

Gambar 3. Pemetaan attribut rekrutmen karyawan.

\section{Dimensional Data Modeling}

Skema yang digunakan untuk membuat data model adalah star schema, di mana terdapat satu fact table dan beberapa dimension table. Menggunakan star schema memungkinkan untuk menganalisis data dari berbagai dimensi. Fact table merupakan tabel yang digunakan untuk menghubungkan data yang terkait digunakan dalam aktifitas rekrutmen karyawan. Dimension table adalah tabel yang berisi data yang menampilkan pandangan dari berbagai sudut pandang. Dengan adanya dimension table memungkinkan untuk membuat laporan yang bersifat dinamis dari berbagai sudut pandang.

Skema bintang memiliki tabel fakta Penilaian. Tabel dimensi yang digunakan terdiri atas: dimensi jabatan, departemen, pelamar dan waktu (Gambar 4).

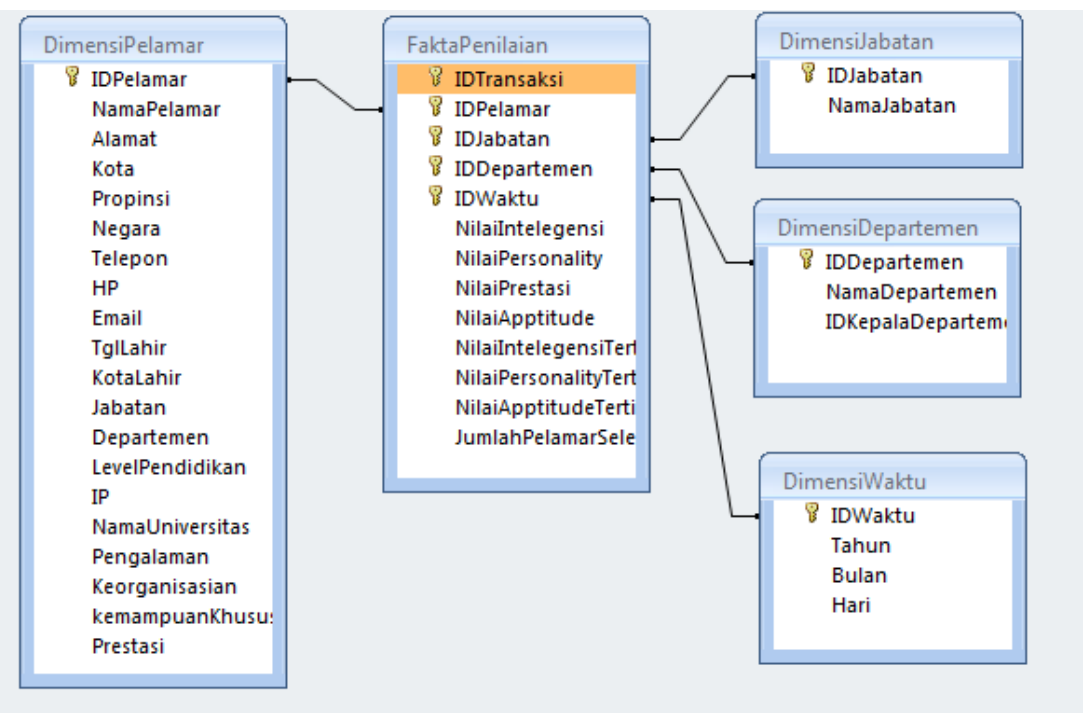

Gambar 4. Skema bintang kegiatan rekrutmen dan penilaian karyawan. 


\section{Layar Tampilan Informasi dari Analisis Informasi yang Dibutuhkan}

Berikut adalah beberapa rancangan layar grafikal yang dibuat berdasarkan kebutuhan yang telah didefinisikan, yang ditampilkan dalam pivot table (Tabel 1 - 3) dan chart (Gambar 5 - 7).

Tabel 1

Rancangan Antar Muka Pivot Table Informasi Jumlah Pelamar per Jabatan pada Waktu Tertentu

\begin{tabular}{|l|r|r|r|}
\hline Count of IDPelamar & IDWaktu & \\
\hline IDJabatan & 1 & 2 & \\
\hline MNGR & 1 & 1 & 2 \\
\hline SPVR & & 1 & 1 \\
\hline STFF & 1 & 1 & 2 \\
\hline Grand Total & 2 & 3 & 5 \\
\hline
\end{tabular}

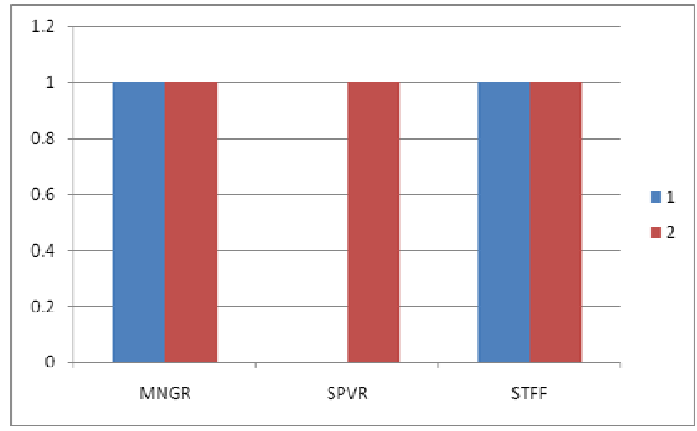

Gambar 5. Rancangan antar muka chart informasi jumlah pelamar per jabatan pada waktu tertentu.

Tabel 2

Rancangan Antar Muka Pivot Table Informasi Jumlah Pelamar per Departemen pada Waktu Tertentu

\begin{tabular}{|l|r|r|r|}
\hline Count of IDPelamar & IDWaktu \\
\hline IDDepartemen & \multicolumn{2}{|l|}{2} & Grand Total \\
\hline D01 & 1 & 1 & 2 \\
\hline D02 & 1 & & 1 \\
D03 & & 1 & 1 \\
\hline D04 & & 1 & 1 \\
\hline Grand Total & 2 & 3 & 5 \\
\hline
\end{tabular}

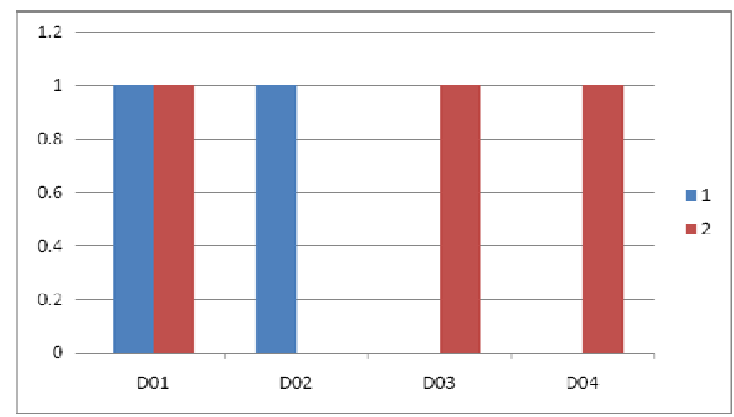

Gambar 6. Rancangan antar muka chart informasi jumlah pelamar per departemen pada waktu tertentu. 
Tabel 3

Rancangan Antar Muka Pivot Table Informasi Jumlah Pelamar per Departemen dan Jabatan pada Waktu Tertentu

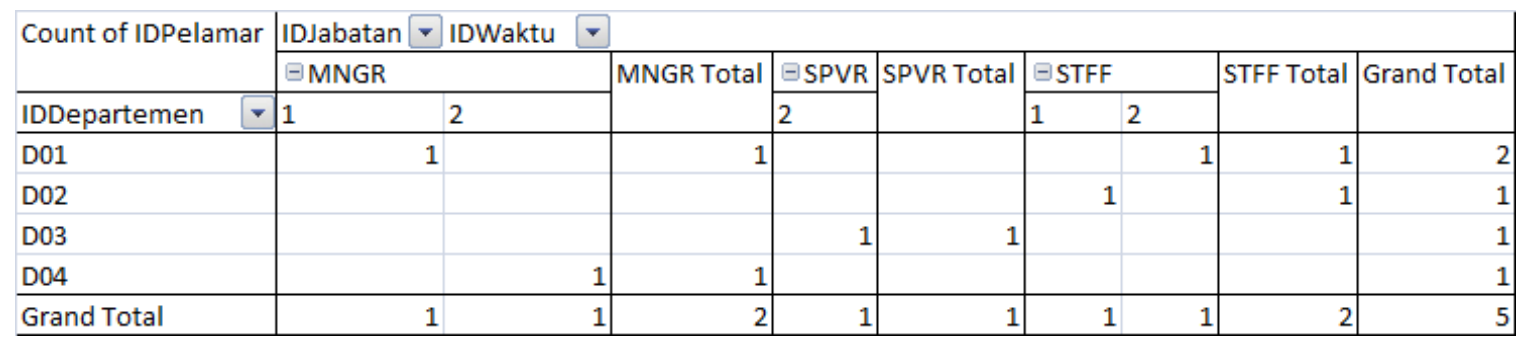

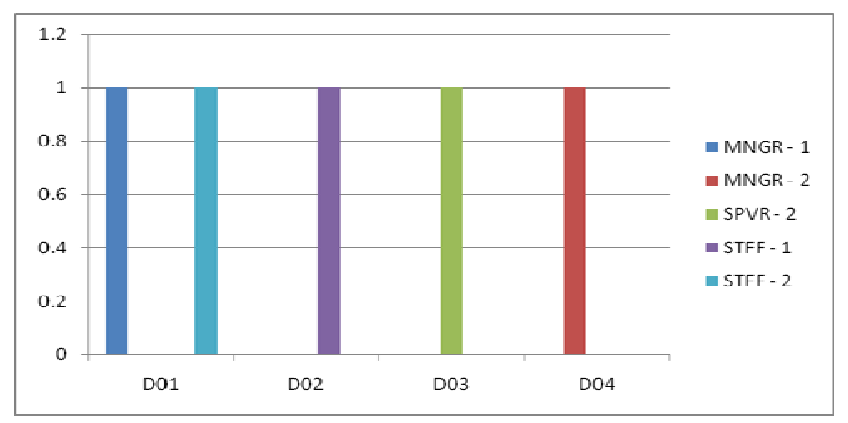

Gambar 7. Rancangan antar muka chart informasi jumlah pelamar per departemen dan jabatan pada waktu tertentu.

\section{PENUTUP}

Data warehouse dapat digunakan untuk menyimpan data dalam jumlah besar dan juga berpotensi untuk mendapatkan sudut pandang baru dari sebaran data, dan memungkinkan untuk memberikan pelaporan dan jawaban dari pertanyaan pengguna yang bersifat ad hoc termasuk juga untuk melakukan analisis terhadap record kegiatan perekrutan dan pengelolaan karyawan untuk mendukung pengambilan keputusan pada departemen Sumber Daya Manusia.

Dalam pembangunan data warehouse departemen Sumber Daya Manusia dengan fokus pada kegiatan rekrutmen terdapat tahapan-tahapan yang dapat dipenuhi untuk memastikan agar pengembangannya mencapai hasil sebagaimana yang diinginkan. Secara garis besar, tahapan meliputi: Pengumpulan data menggunakan teknik wawancara dan studi pustka terkait dengan perekrutan karyawan dan Perancangan data warehouse menggunakan tahapan perancangan data warehouse yang bersumber dari Teh Ying Wah et al. (2007).

Skema bintang yang digunakan dalam perancangan data warehouse departemen Sumber Daya Manusia dengan fokus pada kegiatan rekrutmen terdiri atas tabel dimensi pelamar, jabatan, departemen dan waktu. Sedangkan tabel fakta yang dapat digunakan adalah fakta Penilaian. Dari tabel-tabel fakta dan dimensi itu kemudian dibuat rancangan layar grafikal untuk mendapatkan dan menampilkan informasi-informasi yang bermanfaat bagi departemen Sumber Daya Manusia untuk melakukan perekrutan dan pengelolaan karyawan dengan baik. 


\section{DAFTAR PUSTAKA}

Mallach, Efrem G. (2000). Decision Support and Data Warehouse Systems. New York: McGraw-Hill.

Riyanto, Tikno \& Sucahyo, Yudho Giri. (2006). Pengembangan data warehouse untuk mendukung pengambilan keputusan dalam mengelola sumber daya manusia: sebuah studi kasus pada TNI Angkatan Udara. Jurnal sistem Informasi dan Manajemen Teknologi Informasi, 2 (2). Washington: Healing Mountain Publishing.

Teh Ying Wah, Ng Hooi Peng, \& Ching Sue Hok. (2007). Building data warehouse. Proceedings of the 24th South East Asia Regional Computer Conference, Bangkok, Thailand.

Vercellis, Carlo (2009). Business Intelligence: Data Mining and Optimization for Decision Making. New Jersey: John Wiley and Sons. 